\title{
Effect of Fluoride Mouth Rinse on Fluoride Releasing and Recharging from Aesthetic Dental Materials
}

\author{
Linlin HAN, Edward $\mathrm{CV}^{1}, \mathrm{Mu} \mathrm{LI}$, \\ Kazuaki NIWANO, Neamat $\mathrm{AB}^{2}$, Akira OKAMOTO, \\ Naoko HONDA and Masaaki IWAKU \\ Division of Cariology, Department of Oral Health Sciences \\ Niigata University Graduate School of Medical and Dental Science \\ 5274, Gakkocho-dori 2-bancho 951-8514, Niigata, Japan \\ ${ }^{1}$ Manila Central University College of Dentistry \\ E.D.S.A., Caloocan City, the Philippines \\ ${ }^{2}$ Department of Oral Rehabilitation, \\ Faculty of Dentistry, University of Khartoum, Sudan
}

Received June 10, 2002/Accepted September 30, 2002

\begin{abstract}
This study evaluated fluoride-release and recharging with the fluoride mouth rinsing technique on fluoridated materials. Three fluoride containing materials and one non-fluoride containing composite resin were used for this study. Samples for each material consisted of 15 discs, 9 $\mathrm{mm}$ diameter with a thickness of $1 \mathrm{~mm}$. Initial fluoride release was assessed over a 60-day period. After that, 15 discs for each material were divided into 3 groups: distilled water group, 450 -ppm and 900 -ppm mouth rinsing groups. Fluoride release increased in combination with fluoride mouth rinse, and fluoride was higher in the $900-\mathrm{ppm}$ group than the 450 -ppm group. Moreover, S-PRG or F-PRG fillers materials released fluoride in higher than fluoroaluminosilicate glass fillers materials. In addition fluoride release from control samples was not observed. Therefore, only fluoride release material takes up fluoride. The findings of the present investigation suggest that the rate of fluoride release was different for each material, because they contained different function fillers. The results showed the importance of the fluoride mouth rinsing technique for fluoride-releasing restorative materials for the prevention of secondary caries.
\end{abstract}

Key words: Fluoride release, Fluoride recharging, Fluoridated restorative materials

\section{INTRODUCTION}

At present, many fluoride containing restorative dental materials have been developed, such as glass-ionomer cements, resin-modified glass-ionomers, resin-modified composite and fluoride containing composites resins, because of their evident effectiveness in caries inhibition ${ }^{1-5)}$. Fluoride release is a frequent property of most tooth-colored restorations, the behavior of fluoride release was originally particular to glass-ionomer cements. The main characteristic of the fluoride containing materials consists of fluoride ions release into the oral environment, which are taken up by the tooth structure at the interface of the dental restorative material and the enamel or dentin. The fluoride-releasing restorative materials are of great importance in the prevention of secondary caries around existing restorations and the initial caries of 
enamel and dentin ${ }^{6-11)}$.

Fluoride-releasing restorative materials release fluoride ions, which are taken up by the tooth structure around the restoration. However, unfortunately, most studies have suggested that the majority of fluoride is released within the 1st day after placement ${ }^{12,13)}$. From the results of both in vivo and in vitro experiments, the concentration of fluoride release from the materials rapidly fell to a trough plateau, although its release continued for periods from 2 months to several years ${ }^{12,14,15)}$. However, fluoride release from fluoridated materials may not last for a long time, considering that they are depleted of fluoride. It was suggested that fluoridereleasing materials may continue to release fluoride ions, if they take up fluoride ions. Fluoride release may be sustained on a long-term basis in these materials by supplying and recharging them with fluoride ions following its relative exhaustion. If fluoride was replenished (fluoride recharge) by immersion in fluoride solution, then the exhausted fluoride release of the fluoride containing materials may be continued. Using this method, the fluoride-releasing materials released fluoride ions for comparatively long periods, being effective for the prevention of secondary caries around fluoridated restorative materials ${ }^{16-18)}$.

In a previous study, the fluoride containing material was stored in a high-density fluoride solution for a short time leading to fluoride ion uptake. However, there have been no investigations on influence of the mouth rinses with fluoride ion solutions on the fluoride containing restorative materials. Furthermore, the fluoride containing composite resin material was recently developed.

The aims of this in vitro study were: to assess the characteristics of the concentration and duration of fluoride release from the newly developed fluoridated materials; and secondly, to assess quantitatively the abilities of a range of fluoridated restorative materials to uptake (recharge) and release (re-release) fluoride ions,

Table 1 Materials used in the study

\begin{tabular}{|c|c|c|c|c|}
\hline Material & Type & Code & Manufacturer & Batch No. \\
\hline Beautifil & $\begin{array}{l}\text { Fluoridated composite resin } \\
\text { Contains: S-PRG fillers }\end{array}$ & BTF & Shofu, Tokyo, Japan & 08992728 \\
\hline Unifil S & $\begin{array}{l}\text { Fluoridated composite resin } \\
\text { Contains: fluoroaluminosilicate } \\
\text { glass fillers }\end{array}$ & UNF & $\begin{array}{l}\text { GC Corporation } \\
\text { Tokyo, Japan }\end{array}$ & 9905311 \\
\hline Fuji II LC & $\begin{array}{l}\text { Resin-modified glassionomer } \\
\text { Contains: aluminum, silicat, } \\
\text { sodium }\end{array}$ & FIILC & $\begin{array}{l}\text { GC Corporation } \\
\text { Tokyo, Japan }\end{array}$ & 080191 \\
\hline Reactmer & $\begin{array}{l}\text { Fluoridated resin-modified com- } \\
\text { posite } \\
\text { Contains: F-PRG fillers }\end{array}$ & $\mathrm{RCT}$ & Shofu, Tokyo, Japan & 099900 \\
\hline $\begin{array}{l}\text { Clearfil AP-X } \\
\text { (for control) }\end{array}$ & $\begin{array}{l}\text { Composite resin } \\
\text { Non-fluoride containing }\end{array}$ & APX & Kuraray, Osaka, Japan & 0436AA \\
\hline
\end{tabular}

S-PRG: Surface reaction type pre-reacted glass-onomer

F-PRG: full reaction type pre-reacted glass-ionomer 
after fluoride ions were released to relative exhaustion from those materials.

\section{MATERIALS AND METHOD}

The materials used in this investigation are given in Table 1. Two fluoridated composite resin materials (BTF and UNF), one resin-modified composite (RCT) and one resin-modified glass-ionomer cement (FIILC) were used. Furthermore, a nonfluoridated containing composite resin of the restorative material (Clearfil AP-X) was used as a control.

The following investigations about fluoride release and recharge were conducted:

\section{Fluoride release}

Samples were prepared using a plastic ring mould with an internal diameter of $9 \mathrm{~mm}$ diameter with a thickness of $1 \mathrm{~mm}$. The mould with test materials was held between two glass slides and covered with a transparent polyester strip. Materials were manipulated according to the manufacturers' instructions. A silk thread was placed that could be used to suspend the specimen in the solution after the material had set. The beakers had tightly fitting lids to prevent evaporation of the solution. Samples were stored in distilled water $(10 \mathrm{ml})$ at a temperature of $37^{\circ} \mathrm{C}( \pm 0.5)$ for $1,10,20$, $30,40,50$ and 60 days. Fluoride release was assessed over a 60-day period for all materials. Each specimen was stored in $10 \mathrm{ml}$ of distilled water within a plastic vial. The solutions were changed daily up to day 15, and thereafter every 3 and 4 days until the end of the test with fresh distilled water. The solutions were changed to fresh distilled water 24 hours before the fluoride ion measurements.

Fifteen samples were prepared for each test material.

Standard solutions of sodium fluoride with $0.1,1,10$ and $100 \mathrm{ppm}$ were used to which TISAB III (total ionic strength adjustor and buffer, Orion, Boston, USA) were added in order to obtain a constant background ionic strength.

The standard solutions were used to plot the calibration graph. The fluoride release was detected using a fluoride ion selective electrode (9609BN, Orion Model $290 \mathrm{~A}$, USA) connected to a microprocessor ion analyzer (Orion model 290A, USA). The test samples were placed on a non-heating magnetic stirrer (AT 1 model AS 1, Kanazawa, Japan) to obtain an even distribution of the fluoride ion. The temperature of the solution was adjusted to $23^{\circ} \mathrm{C}( \pm 2)$. Mean values of the fluoride concentration were calculated to express fluoride release in $\mu \mathrm{g} / \mathrm{cm}^{2}$.

\section{Fluoride recharge}

The test samples (fifteen samples) were those obtained in test 1 by storing in distilled water for 60 days, to allow the majority of the fluoride to leach out from the materials. These samples were stored in fluoride mouth rinse solutions in concentrations of 450 and 900 -ppm for 20 days, which was the period of fluoride recharge. The fifteen samples of each material were divided into three groups, five samples, stored in distilled water, served as controls, and the other ten samples were divided 
in two test groups: one stored in 450-ppm and the other in 900-ppm fluoride solution. On a daily basis over the 20-day experimental period, all test groups were stored in $10 \mathrm{ml} 450$-ppm or 900 -ppm fluoride solution for $2 \mathrm{~min}$, and the control samples were stored in distilled water for $2 \mathrm{~min}$. Thereafter, these samples were dabbled and stored individually into $2 \mathrm{ml}$ of fresh distilled water; blotting the samples dry before storing them in fresh water, to minimize crossover contamination. This procedure was repeated each day for all samples until the end of the test. Fluoride release after recharging was assessed from the $2 \mathrm{ml}$ of distilled water in which the samples had been stored for $24 \mathrm{~h}$. The stored samples solutions were changed for fresh distilled water after each test. The method of fluoride analyses followed the procedure outlined in test 1.

Data were analysed by one-way analysis of variance (AVOVA) and $t$-test, with the level of significance set at $5 \%$.

\section{RESULTS}

\section{Initial fluoride release}

In the Table 2 displays the concentrations of fluoride released by each material from day-1 until to day-60. All tested materials released measurable amounts of fluoride throughout the test period, with a considerable range on 1-day $(3.15-67.16 \mu \mathrm{gF})$. The concentration of fluoride release on 7-day fell sharply for all materials (2.01-17.22 $\mu \mathrm{gF})$, but all materials continued. to release fluoride until over 60 days, although to a lesser extent $(0.79-9.12 \mu \mathrm{gF})$. Fluoridated composite resin UNF showed the lowest original fluoride concentration $(3.15 \mu \mathrm{gF}$ on the first day) and continued to be the lowest throughout the test period $(0.79 \mu \mathrm{gF}$ on 60 -day). Fluoridated composite resin BTF released a higher amount of fluoride especially on the first day; the rate of fluoride released was $9.32 \mu \mathrm{gF}$, and $2.98 \mu \mathrm{gF}$ after 60 days. On the other hand, it was noted that FIILC (resin-modified glass-ionomer) exhibited the highest rate of fluoride release $(67.16 \mu \mathrm{gF}$ on first day) that continued throughout the 60 -day period (9.12 $\mu \mathrm{gF})$. Fluoridated resin-modified composite RCT release fluoride level was lower than FIILC $(12.31 \mu \mathrm{gF}$ on the first day and $2.56 \mu \mathrm{gF}$ after 60 days), but the fluoride release maintained a higher ratio compared with $\mathrm{BTF}$ or UNF.

Table 2 Fluoride release in the fluoride containing restorative materials (means $\pm \mathrm{SD}$ )

\begin{tabular}{|c|c|c|c|c|}
\hline period ${ }^{\text {materials }}$ & BTF & UNF & FIILC & RCT \\
\hline 1 day & $9.32(1.02)$ & $3.15(0.41)$ & $67.16(8.98)$ & $12.31 \quad(0.88)$ \\
\hline 10 days & $5.52 \quad(0.36)$ & $2.01 \quad(0.32)$ & $17.22(2.21)$ & $6.35(0.54)$ \\
\hline 20 days & $4.56(0.28)$ & $1.22(0.08)$ & $15.15(2.12)$ & $5.12(0.16)$ \\
\hline 30 days & $3.32(0.35)$ & $1.05 \quad(0.12)$ & $12.88(0.89)$ & $3.77(0.45)$ \\
\hline 40 days & $3.35(0.41)$ & $0.98(0.11)$ & $10.35(1.85)$ & $2.98(0.15)$ \\
\hline 50 days & $3.21 \quad(0.26)$ & $0.81 \quad(0.09)$ & $10.11 \quad(1.56)$ & $2.75(0.17)$ \\
\hline 60 days & $2.98(0.18)$ & $0.79(0.06)$ & $9.12(0.69)$ & $2.56 \quad(0.31)$ \\
\hline
\end{tabular}




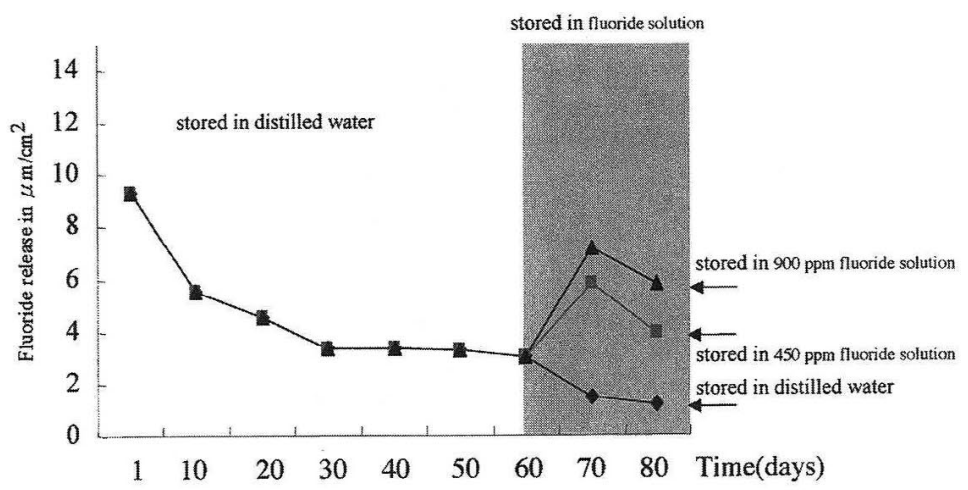

Fig. 1 Fluoride release and recharging in the fluoride containing composite resin (BTF).

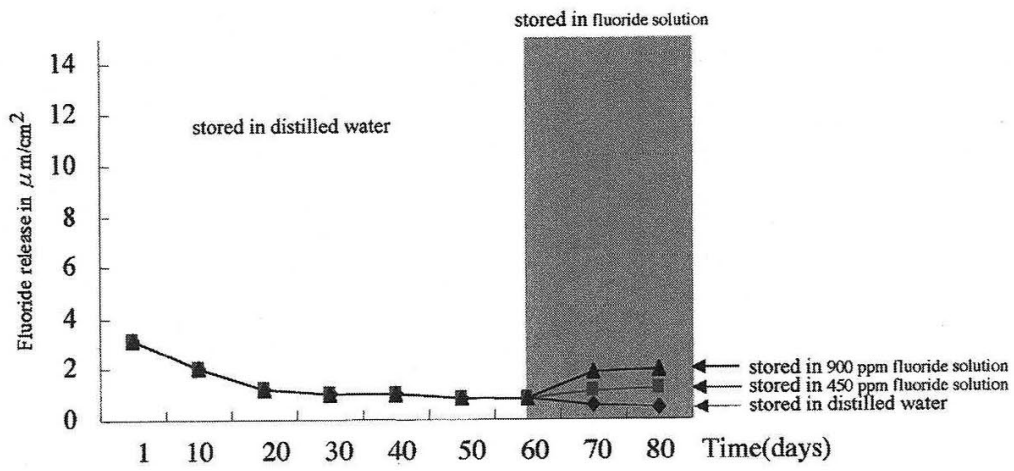

Fig. 2 Fluoride release and recharging in the fluoride containing composite resin (UNF).

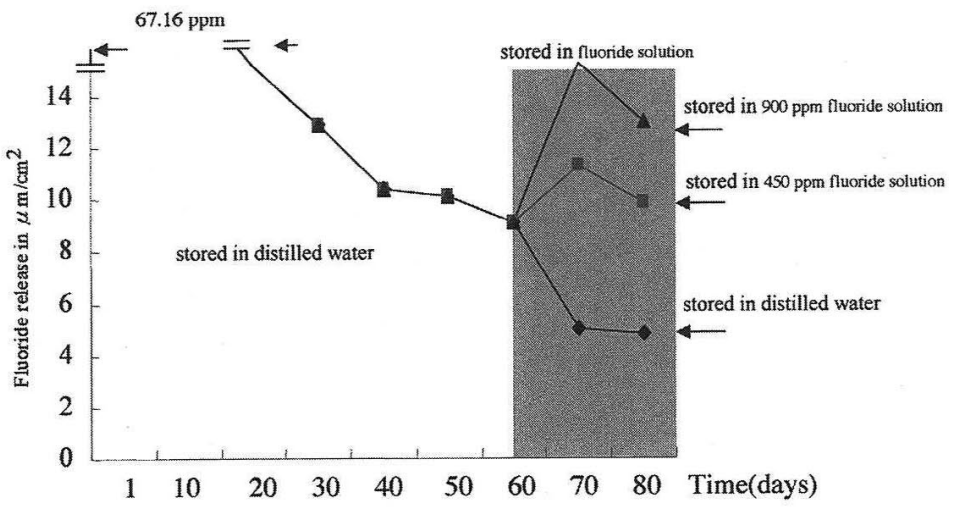

Fig. 3 Fluoride release and recharging in the resin-modified glass-iomomer cement (FIILC). 


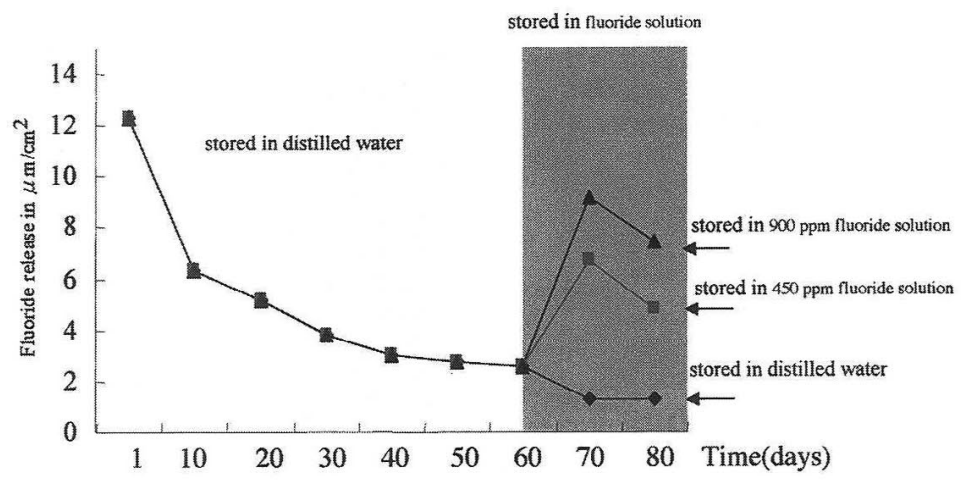

Fig. 4 Fluoride release and recharging in the resin-modified composite ( $\mathrm{RCT}$ ).

Table 3 Fluoride release after recharging (after released fluoride is relatively exhausted and stored in distilled water from day 60 until day 80 ) in the fluoride containing restorative materials (means \pm SD)

\begin{tabular}{c|c|c|c|c|c|c|c|c|c|c|c|c}
$\begin{array}{c}\text { materials } \\
\text { period }\end{array}$ & BTF & BTF450 & BTF900 & UNF & UNF450 & UNF900 & FIILC & FIILC450 & FILC900 & RCT & RCT450 & RCT900 \\
\hline 61 days & $1.45(0.21)$ & $4.21(0.41)$ & $7.21(0.68)$ & $0.55(0.05)$ & $1.25(0.25)$ & $1.78(0.07)$ & $8.99(1.14)$ & $10.66(1.28)$ & $15.77(1.01)$ & $2.22(0.39)$ & $6.25(0.83)$ & $9.75(0.89)$ \\
65 days & $1.47(0.24)$ & $5.89(0.59)$ & $7.52(0.81)$ & $0.52(0.11)$ & $1.28(0.24)$ & $1.95(0.25)$ & $5.21(0.77)$ & $10.25(0.92)$ & $15.29(1.61)$ & $1.33(0.32)$ & $7.41(0.46)$ & $10.12(0.72)$ \\
70 days & $1.46(0.19)$ & $5.76(0.76)$ & $7.11(0.79)$ & $0.51(0.12)$ & $1.15(0.12)$ & $1.85(0.16)$ & $1.98(0.59)$ & $11.33(1.48)$ & $15.25(1.98)$ & $1.28(0.12)$ & $6.65(0.66)$ & $9.15(0.84)$ \\
75 days & $1.35(0.17)$ & $4.95(0.59)$ & $6.98(0.82)$ & $0.46(0.06)$ & $1.19(0.18)$ & $1.88(0.26)$ & $1.88(0.85)$ & $10.71(1.25)$ & $15.16(1.21)$ & $1.27(0.28)$ & $6.12(0.47)$ & $8.61(0.75)$ \\
80 days & $1.21(0.21)$ & $4.69(0.56)$ & $6.56(0.71)$ & $0.45(0.06)$ & $1.16(0.13)$ & $1.92(0.21)$ & $4.75(0.39)$ & $9.79(0.54)$ & $14.01(1.17)$ & $1.26(0.25)$ & $5.56(0.62)$ & $7.38(0.37)$ \\
\hline
\end{tabular}

Control material AP-X has no data in the table, because it did not release fluoride after storing in fluoride mouth rinse solution.

There was no fluoride released from the control samples (APX; $0 \mu \mathrm{gF}$ ).

\section{Fluoride recharge}

Figs. 1-4 and Table 3 show the concentration of fluoride release after the samples were recharge with the fluoride solution mouth rinse technique during the 61-day to 80-day period after test 1 (continued use of the test 1 samples).

The test samples were exposed to fluoride solutions of 450-ppm and 900-ppm. BTF showed a higher concentration of fluoride release after application of the fluoride mouth rinse solution on day 61 , and maintained a higher concentration up to day 80 . BTF samples that were stored in the $900-\mathrm{ppm}$ fluoride solution showed a higher rate of fluoride release, than those stored in the 450-ppm fluoride solution.

The UNF of 900-ppm group showed a higher rate of fluoride release compared with the 450-ppm group after application of fluoride solution from day 61 until day 80. UNF initial fluoride release was lower than that of BTF, but rate of the fluoride release was the similar to as that of BTF.

FIILC showed the highest rate of fluoride release after application of 900-ppm 
and 450-ppm fluoride solution in the all test groups. The 900-ppm samples showed a higher rate than those stored in the 450 -ppm fluoride solution during the test period (61-80-day period).

RCT showed a higher concentration of fluoride release after the application of fluoride solution from day 61 and maintain the higher rate of fluoride release up to day 80. Thus, samples stored in $900-\mathrm{ppm}$ fluoride solution showed a higher rate of fluoride release compared with 450 -ppm samples.

The concentration of fluoride release was higher with the $900-\mathrm{ppm} \mathrm{F}$ applied fluoride solution than 450 -ppm $\mathrm{F}$ in all test groups (without AP-X of control material). These samples consistently released ionic fluoride compared with that stored in distilled water during the test period, that is, the rate of the samples (stored in distilled water) release fluoride was lower compared with the mouth rinse groups after recharging.

The control samples $(\mathrm{AP}-\mathrm{X})$ did not release fluoride during the whole test period (before and after application of the fluoride solution).

\section{DISCUSSION}

Recently, resin-modified glass-ionomer, resin-modified composite (compomer) and fluoridated composite resin have been developed. They attempt to improve the mechanical and physical properties of restorations, compared with conventional glassionomers. The fluoride release from these materials has been the subject of much attention from the view of caries inhibition. At present, research has focused on fluoride containing materials that can be recharged after exposure to fluoride solutions ${ }^{16,19)}$, when to allow the majority of the fluoride to leach out from the materials. The results of this investigation have shown that fluoride contain restorative materials can continue to release fluoride ions after fluoride recharging for longer than non-recharged samples and non-fluoride containing restorative materials.

However, the amount of fluoride released varied siginficantly between materials. The amount of initial fluoride release was higher from resin-modified glass-ionomer cements FIILC (highest) and resin-modified composite RCT, compared with fluoridated composites (BTF and UNF).

The amount of initial fluoride release from RCT was lower than that of FIILC, but, remained higher rate of fluoride release before and after the application of fluoride solution compared with BTF or UNF.

In this study resin-modified glass ionomer cement, resin-modified composite and new lydeveloped fluoridated composite resins were used. FIILC is a resin-modified glass-ionomer cement. Its fluoride release was highest $(67.16 \mu \mathrm{gF}$ on the first day of the initial fluoride release) of all test materials.

Usually, fluoride-releasing materials contain fluoride silica, fluoride aluminum, fluoride calcium and fluoride sodium fillers (e.g. glass ionomer cements) or fluoride releasing polymer (e.g. sealant ${ }^{20)}$. The newly developed fluoridate restorative materials include the fluoroaluminosilicate glass fillers type and S-PRG (Surface reaction 
type Pre-Reacted Glass-ionomer) or F-PRG (Full reaction type Pre-Reacted Glassionomer) fillers types.

Previously, fluoride release was easier and higher from the glass-ionomers materials than contain fluoridated polymer materials ${ }^{21)}$. Glass-ionomer contain fluoridated silica, aluminum or sodium fillers. Those fluoridated fillers dissolve easier when in contact with water, and release fluoride ions thereafter (for example: this may occur in cases of microleakage in marginal zones of restorations). The released fluoride ions from the material, could be uptake, by the enamel or dentin interface (between the material and enamel or dentin interface) and the acid resistance of the enamel and dentin is improved. This is the reason why fluoride releasing materials can prevent tooth caries $^{22,23)}$. The characteristics of fluoridated silica, aluminum or sodium fillers easily release of fluoride ions if they contact moisture, and also easily uptake fluoride ions into the silica, aluminum and sodium fillers when in contact with fluoride ions (in moisture conditions). This test of fluoride recharging by the mouth rinsing technique used the fluoride release and recharging characteristics of glass-ionomer cements.

RCT is a resin-modified composite and contains fillers of F-PRG (full reaction type Pre-Reacted Glass-ionomer). F-PRG fillers facilitate combinations with the base resin of the material and also maintain the fluoride-releasing characteristics of the original glass ionomer. RCT is a resin-modified composite that retained some characteristics of the glass-ionomer, for example, it contains inorganic substance filler. Conventionally, conventional glass-ionomer cement is deteriorated after releasing fluoride ions, because the fluoridated filler is recharged if it encounters moisture. However, RCT was not damaged after releasing fluoride ions, because was fluoride released only from surface of the F-PRG fillers. Consequently, RCT released fluoride was lower than FIILC, but the rate of the fluoride released after recharging was proportional (compared with FIILC).

In this study, two fluoride containing composite resins were used (BTF and UNF). The of concentration of fluoride released was higher in BTF than in UNF. The difference in the amount of fluoride released could be due to the relation between the base material and the type of fluoridated filler. BTF contain S-PRG (Surface reaction type Pre-Reacted Glass-inonmer) fillers, and maintains characteristics of the glass-ionomer cements. Therefore, BTF fluoride release may have been easier.

UNF contains fluoroaluminosilicate glass fillers in the base resin. Thus, the fluoride ions may have been shut off in the resin base and are difficult to release from UNF. Maybe, this explains the lower fluoride release rate from the UNF.

The amount of fluoride recharge was measured after application of the fluoride mouth rinse solution. The concentration of the fluoride solutions used were 450- and 900-ppm because the concentrations of the fluoride in fluoridated toothpaste or school mouth rinse ranges between 450 and 900 (or 1000) ppm F. The results of fluoride recharging are shown in Figs. 1-4 and 3. The amount of fluoride released after recharging was higher in the RCT and BTF (fluoridated F-PRG and S-PRG fillers type materials) compared with UNF (fluoroaluminosilicate glass fillers type mate- 
rial). BTF and UNF are both fluoridated composite resin materials. BTF contains S-PRG that probably helped to release or recharge fluoride ions easily. Considering that $\mathrm{BTF}$ and $\mathrm{UNF}$ are composite resin materials, the ratio of fluoride release or the fluoride recharging properties were lower than resin-modified glass-ionomer materials. This possible relates to the volume of the base resin and the kind of fillers. In addition, the ratio of fluoride release was highest for the FIILC after fluoride recharging.

The results of fluoride recharging in the fluoridated materials after exposure to fluoride solutions were dependent on the concentration of the fluoride ions and the material (filler) type. The ratio of fluoride release after exposure to fluoride solution (recharge) in the test material was higher in $900-\mathrm{ppm} \mathrm{F}$ than 450 -ppm $\mathrm{F}$, and was also higher than the samples were stored in distilled water.

The control APX sample in fluoride released and recharged was zero.

The ratio of fluoride release was higher after recharging in the resin-modified type of material, due to the ease of diffusion of fluoride ions for F-PRG or S-PRG silica gel fillers. However, the concentration of fluoride release decreased each day after exposure to fluoride solution (recharging). This may be due to silica fillers changing to the stable fluoride silica on the surface the structural of material.

These fluoride-releasing restorative materials used in clinical dental practice promote fluoride ion uptake by enamel or dentin, thereby improving acid resistance, and thus increasing their potential in reducing the incidence of dental caries ${ }^{24)}$. Therefore, fluoride-releasing restorative materials are worthy of investigation because they were suggested to possess recurrent caries-inhibiting properties.

Composite resin restorations do show problems with time following application as a result of microleakage, nanoleakage and insufficient marginal adaptation. Recently, it was reported that fluoride-releasing composite restorations reduced the lesion depth and mineral loss of adjacent enamel by about $30 \%$ in in vitro studies $^{25-27)}$. However, the fluoride release was limited in fluoridated resin type materials. The present study showed the extent by which the fluoride-releasing capacity was affected by the fluoride solution recharging method. If fluoride mouth rinse is used continuously, it is useful and beneficial for preventing secondary caries or initial caries around the margin of restorations in both enamel and dentin ${ }^{26-28)}$. The mechanism of action of fluoride in caries reduction is not fully understood; the optimum fluoride concentration for caries inhibition is unknown. In addition, the mechanism for decreasing in secondary decay around restorations of fluoride-releasing materials is not well understood and clinical studies on fluoridated materials are lacking. However, fluoride-releasing composites appear to have a local positive effect on the demineralization process of enamel and dentin, and may have a role to play in the future prevention of secondary caries ${ }^{29)}$. This may be effective in decreasing secondary decay around fluoride containing resin-modified glass-ionomer cement or resin composite restorations, if used in combination with the fluoride solution mouth rinsing technique. 


\section{CONCLUSIONS}

In this study, fluoridated restorative materials release fluoride and increase the release of fluoride ions after the application of fluoride mouth rinsing solution. The ratio of fluoride release after recharging depends on the fluoride concentration of the fluoride solution and the function fillers in the base materials and maybe relate to the base resin content. The ratio of fluoride release after recharging was higher when treated by high concentrations of fluoride solution. The results suggested that the fluoride-releasing restorative materials might improve the extent of fluoride release after fluoride recharging by mouth rinsing with fluoride solution.

\section{REFERENCES}

1) Retief, D. H. and Bradley, E. L.: Enamel and cementum fluoride uptake from a glassionomer cement, Caries Res $18: 250-257,1984$.

2) Forss, H.S.: Prevention of enamel demineralization adjacent to glass-ionomer filling materials, Scand $J$ Dent Res $98: 173-178,1990$.

3) Griffin, E., Donly, K. J. and Erickson, R.: Caries inhibition by fluoride-releasing liners, Am J Dent 5 : 293-295, 1992.

4) Donly, K. J.: Enamel and dentin demineralization inhibition of fluoride-releasing materials, J Dent $7: 275-278,1994$.

5) Swartz, M. L., Phillips, R.W. and Clark, H. E.: Long-term F release from glass-ionomer cements, J Dent Res 63 : 158-160, 1984.

6) Hicks, M. J., Flaitz, C. M. and Silverstone, L. M.: Secondary caries formation in vitro around glass ionomer restorations, Quintessence Int $17: 527-531,1986$.

7) Skartveit, L., Tveit, A. B., Totdal, B., Ovrebo, R. and Raadal, M.: In vivo fluoride uptake in enamel and dentine from fluoride-containing materials, $J$ Dent Child 57:97-100, 1990.

8) Billings, R.J.: Restoration of carious lesions of the root, Gerontology $5: 43-49,1986$.

9) Mount, G. J.: Glass ionomer cement in gerodontics: A status report for the American Journal of dentistry, Am J Dent $1: 123-128,1988$.

10) Phillips, R. W.: Restorative materials containing fluoride, $J$ Am Dent Assoc 116 : 762-763, 1988.

11) Forsten, L.: Fluoride release and uptake by glass-ionomer, Scand J Dent Res 99 : 241-245, 1991.

12) Cooley, R. L. and McCourt, J. W.: Fluoride releasing removable appliances, Quintessence Int 22 : 299-302, 1991.

13) DeSchepper, E. J., Berr, E. A., Cailleteau, J. G. and Tate, W. H.: A comparative study of fluoride release from glass-ionomer cement, Quintessence Int $22: 215-219,1991$.

14) Forsten, L.: Short and long-term fluoride release from glass ionomer based liners, Scand $J$ Dent Res 99 : 340-342, 1991.

15) Hatibovic-Kofman, S. and Koch, G.: Fluoride release from glass ionomer cement in vivo and in vitro, Swed dent $15: 253-258,1991$.

16) Forsten, L.: Fluoride release and uptake by glass ionomer, Scand $J$ Dent Res 99 : 241-245, 1991.

17) Creanor, S. L., Carruthers, L. M. C., Saunders, W. P., Strang, R. and Foye, R. H.: Fluoride uptake and release characteristics of glass ionomer cement, Caries Res $28: 322-328$, 1994.

18) Creanor, S. L., Carruthers, L. M. C., Saunders, W. P., Strang, R. and Foye, R. H.: Effect of extrinsic fluoride concentration on the uptake and release of fluoride from two-glass 
ionomer cements, Caries Res 29 : 424-426, 1994.

19) Strother, J. M., Hohn, D. H., Dennison, J. B. and Clarkson, B. H. H.: Fluoride release and re-uptake in direct tooth colored restorative materials, Dent Mater 14:129-136, 1998.

20) Preston, A. J., Higham, S. M., Agala, anyi, E. A. and Mair, L. H.: Fluoride recharge of aesthetic dental materials, J Oral Rehabilitation 26 : 936-940, 1999.

21) Forsten, L.: Short and long-term fluoride release from glass-ionomers and other fluoride-containing filling materials in vitro, Scand $J$ Dent Res 98:179-185, 1990.

22) Takahashi, K., Emilson, C. G. and Birkhed, D.: Fluoride release in vitro from various glass-ionomer cement and resin composites after exposure to NaF solution, Dent Mater 9: 350-354, 1993.

23) Suljak, J.P. and Hatibovic-Kofman, S.: A fluoride release-adsorption-release system applied to fluoride-releasing restorative materials, Quintessence Int 27 :635-638, 1996.

24) Momoi, Y. and McCabe, J.F.: Fluoride release from light-activated glass ionomer restorative cements, Dent Mater 9:151-154, 1993.

25) Gordon, M., Plasschaert, A.J. M. and Stark, M. M.: Microleakage of several toothcoloured restorative materials in cervical cavities: A comparitive study in vitro, Dent Mater $2: 228-231,1986$.

26) Fayyad, M. A. and Shortall, A.C. C.: Microleakage of dentine-bonded posterior composite restorations, $J$ Dent $15: 67-72,1987$.

27) Han, L., Neamat, A. B., Akira, O. and Masaaki, I.: Study on the fluoridated adhesive resin cement - fluoride release, fluoride uptake \& acid resistance of the tooth structures-, Dent Mater $J 20: 114-122,2001$.

28) Arends, J. and Zee, V.D. Y.: Fluoride uptake in bovine enamel and dentin from a fluoride-releasing composite resin, Quintessence Int $21: 541-544,1990$.

29) Donly, K. J.: Enamel and dentin demineralization inhibition of fluoride-releasing materials, J Dent $7: 275-278,1994$.

30) Hotz, P. R.: Experimental secondary caries around amalgam, composite and glass ionomer cement fillings in human teeth, Helvetica Odontologica Acta 23 : 9-39, 1979.

31) Dijkman, G. E. H. M. and Arends, J.: Secondary caries in situ around fluoride-releasing light-curing composites: a quantitative model investigation on four materials with a fluoride content between 0 and 26 vol\%, Caries Res 26:351-357, 1992.

32) Forsten, L.: Resin-modified glass ionomer cement: fluoride release and uptake, Acta Odontol Scand $53: 222-225,1995$.

33) Temin, S. C., Csuros, Z. and Mellberg, J. R.: Fluoride uptake from a composite restorative by enamel, Dent Mater $5: 64-65,1989$. 